\title{
Electrochemical Properties of Tungsten-Alloying-Modified AISI 430 Stainless Steel as Bipolar Plates for PEMFCs used in Marine Environment
}

\author{
Jin-Long Cui ${ }^{1} \cdot$ Zhen-Dong Yao $^{1} \cdot$ Yong-Fu Cui $^{1} \cdot$ Fu-Peng Cheng ${ }^{1} \cdot$ Ting Xiao $^{1} \cdot$ Hong-Liang Sun ${ }^{1} \cdot$ \\ Ru-Jin $\operatorname{Tian}^{2} \cdot$ Jun-Cai Sun ${ }^{1}$
}

Received: 20 March 2016/Revised: 13 June 2016/Published online: 18 July 2016

(c) The Chinese Society for Metals and Springer-Verlag Berlin Heidelberg 2016

\begin{abstract}
To improve the corrosion resistance and surface electrical conductivity of AISI 430 stainless steel (430 SS) as bipolar plates for proton exchange membrane fuel cells (PEMFCs) used in marine environment, a tungsten alloying layer has been successfully prepared on 430 SS substrate via the plasma surface diffusion alloying technique. The tungstenmodified (W-modified) $430 \mathrm{SS}$ displays a 7-8 $\mu \mathrm{m}$ tungsten alloying layer with a body-centered-cubic structure. The W-modified surface also shows a better hydrophobicity with contact angle of $93.5^{\circ}$ and a lower interfacial contact resistance compared with the untreated $430 \mathrm{SS}$. The potentiodynamic and potentiostatic polarization and electrochemical impedance spectroscopy measurements show that the corrosion resistance of $430 \mathrm{SS}$ is obviously improved in simulated PEMFC environment $\left(0.05 \mathrm{M} \mathrm{H}_{2} \mathrm{SO}_{4}+2 \mathrm{ppm} \mathrm{HF}+0.01 \mathrm{M} \mathrm{NaCl}\right.$ solution at $\left.70{ }^{\circ} \mathrm{C}\right)$, after the plasma surface diffusion alloying process.
\end{abstract}

KEY WORDS: Tungsten alloying layer; Corrosion resistance; Proton exchange membrane fuel cell; Interfacial contact resistance; Bipolar plates

\section{Introduction}

Proton exchange membrane fuel cell is considered as an emerging technology for transportation, portable power and household power plant applications [1, 2]. Bipolar plates are very important and multifunctional components in PEMFC stacks. The bipolar plates, which not only contact with an aggressive acid environment, but also conduct electric current from one cell to another, are required to have a strong corrosion resistance and high

Available online at http://link.springer.com/journal/40195

Jun-Cai Sun

sunjc@dlmu.edu.cn

1 Institute of Materials and Technology, Dalian Maritime University, Dalian 116026, China

2 College of Materials Science and Engineering, Dalian Jiaotong University, Dalian 116028, China electric conductivity $[3,4]$. When the $\mathrm{H}_{2}$-air PEMFCs are used as the power source of merchant ships, seashore vehicles and islands, chloride ions $\left(\mathrm{Cl}^{-}\right)$contained in the ocean air can be introduced into PEMFC cathode environment by gas channel of the bipolar plates. In general, the $\mathrm{Cl}^{-}$introduced in the fabrication procedure of membrane electrode assembly (MEA) and catalysts are considered as being little effect on the properties of PEMFCs before. However, the $\mathrm{Cl}^{-}$will increase pitting corrosion of the metals and should be taken into consideration for the bipolar plates, especially metallic bipolar plates [5, 6]. Though the concentration of $\mathrm{Cl}^{-}$in the ocean air is limited, a considerable value can be obtained by a constant accumulation and thus the effect of $\mathrm{Cl}^{-}$on the corrosion of the bipolar plates should be considered [7]. On the contrary, the anode plate is not affected by this part of $\mathrm{Cl}^{-}$during working process due to the resistance of proton exchange membrane [5]. Therefore, the corrosion resistance of the cathode plates becomes more important to the performance of PEMFCs which are used in the marine environment. 
Traditionally, bipolar plates of PEMFCs are made of non-porous graphite, which shows excellent corrosion resistance and low contact resistance in PEMFC environments [8]. However, its low toughness, gas permeability [9] and the difficulties in machining gas flow channels increase fabrication costs, which is an important challenge to wide commercialization use $[10,11]$. Candidate metallic bipolar plate materials, including stainless steels [12], aluminum [13], Ni-Cr alloys [14] and so on, are currently under consideration to substitute for the traditional graphite. Among them, the stainless steel is widely accepted as one of the main PEMFC bipolar plates material candidates due to its suitable mechanical and physical properties as well as relatively low cost $[12,15]$. However, the bare stainless steels cannot be effectively applied into PEMFCs in terms of corrosion resistance. In order to improve the corrosion resistance of the stainless steels in the PEMFCs environment, many researchers have prepared transition metals and their nitrides or carbides protecting layers on the surface of the stainless steels via different methods, such as electroplating [3], magnetron sputtering [16], vapor deposition [17]. Only very few investigators have modified the stainless steels bipolar plates via plasma surface diffusion alloying technique [18-23]. Nonetheless, compared with the inevitable corrosion environment of PEMFCs, the stainless steel bipolar plates used in marine environment will also face a more severe pitting corrosion, which is caused by the increased $\mathrm{Cl}^{-}$in the ocean air [5-7]. This situation has never been considered in all of the finished works, and thus a stronger corrosion resistance layer must be prepared on the surface of bare stainless steels to extend their service life in the marine environment. In this work, we had prepared a cohesive and uniform tungsten alloying layer on the surface of AISI 430 SS via plasma surface diffusion alloying method for improving the electric conductivity and corrosion resistance of $430 \mathrm{SS}$ bipolar plates for PEMFCs which were used in marine environment $\left(0.05 \mathrm{M} \mathrm{H}_{2} \mathrm{SO}_{4}+2 \mathrm{ppm} \mathrm{F}^{-}+0.01 \mathrm{M} \mathrm{NaCl}\right.$ solution$)$.

\section{Experimental}

\subsection{Specimen Preparation}

AISI 430 SS sheets (thickness $1.5 \mathrm{~mm}$ ) were cut into the specimens of $10 \mathrm{~mm} \times 10 \mathrm{~mm}$ via electric discharge machining. The composition of AISI $430 \mathrm{SS}$ is $0.068 \mathrm{C}$, $16.87 \mathrm{Cr}, \mathrm{Ni}<1,0.342 \mathrm{Si}, 0.304 \mathrm{Mn}, 0.027 \mathrm{Cu}, 0.020 \mathrm{P}$ (wt\%), and Fe balanced. The specimens were ground with Nos. 360, 500, 800, 1000, 1500 and 2000 grit SiC abrasive papers, respectively, polished mechanically with diamond paste, cleaned with ethanol in an ultrasonic cleaner and then dried at room temperature.
The tungsten alloying layer was formed on the surface of $430 \mathrm{SS}$ using a double glow plasma alloying furnace which has three electrodes: an anode, a sputtering source cathode (W plate) and a negative cathode (specimens). The structure diagram of plasma surface alloying equipment is shown in Fig. 1. The 430 SS specimens were heated to $1223 \mathrm{~K}$ by power supply, and meanwhile their surfaces were cleaned via ion bombardment in argon-filled chamber at the pressure of $40 \mathrm{~Pa}$ and bias voltage of $-950 \mathrm{~V}$. After keeping the specimens at $1223 \mathrm{~K}$ for $20 \mathrm{~min}$, the working voltage of the specimens was decreased to $-550 \mathrm{~V}$ and then the sputtering source electrode was loaded and kept at $-900 \mathrm{~V}$. All parameters remained in this condition for $2 \mathrm{~h}$ as a tungsten diffusion process.

\subsection{Characterizations}

The surface and cross section of the tungsten alloying layer were analyzed by a scanning electron microscopy (SEM) (SUPRA 55 SAPPHIRE, CARL ZEISS, Germany) in combination with energy-dispersive $\mathrm{X}$-ray analysis spectrometer (EDS) (X-Max, OXFORD, UK). EDS linear scanning was used to detect the variation of tungsten, iron, and chromium elements as a function of distance from the surface of the W-modified 430 SS. The X-ray diffraction (XRD) (RigakuD/ MAX-3A, Rigaku Corporation, Japan) patterns of untreated and $\mathrm{W}$-modified $430 \mathrm{SS}$ were obtained using a $\mathrm{Cu} K_{\alpha}$ radiation $(\lambda=0.15406 \mathrm{~nm})$ at operating voltage of $40 \mathrm{kV}$ and a filament current of $40 \mathrm{~mA}$. The diffraction angle was scanned from $30^{\circ}$ to $125^{\circ}$, at a rate of $6^{\circ} \mathrm{min}^{-1}$. The hydrophilicity of the specimen surfaces was evaluated by contact-angle analysis using the sessile drop method. An equal volume of distilled water was dropped carefully onto each sample by means of a micropipette. All measurements were made using a contact-angle meter (SL200B, Kino, USA).

\subsection{Interfacial Contact Resistance (ICR)}

Interfacial contact resistance (ICR) values of untreated and W-modified 430 SS were determined using the methods

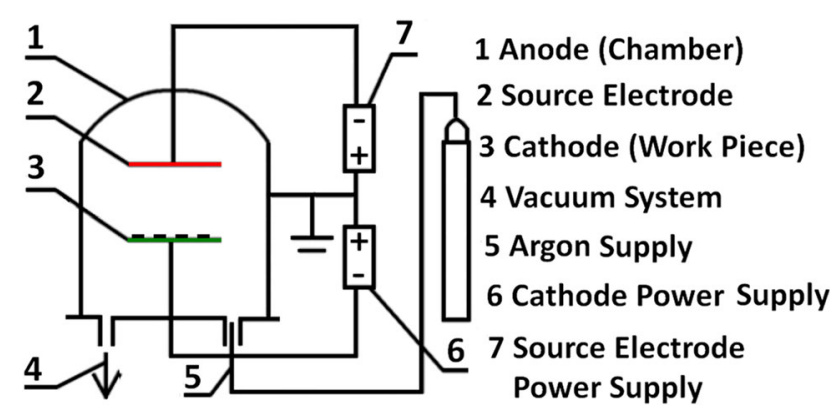

Fig. 1 Structure diagram of plasma surface alloying equipment 
described in detail elsewhere [18]. Briefly, the specimen was sandwiched between two carbon papers (Toray, Inc.) and then the carbon paper/specimen/carbon paper sandwich was put into two copper plates for force loading. Changeable compaction forces were obtained through manually screwing a screw nut and a lead screw whose records were kept by a MCK-C compaction sensor (a special force gauge). A constant current $(0.1 \mathrm{~A})$ sourced by an YJ-10A type galvanostat was used via two copper plates. Simultaneously, the variable potentials were recorded via a Solartron 7081 digital voltmeter with a precision of $10^{-8} \mathrm{~V}$.

\subsection{Electrochemical Measurements}

The specimens were covered with insulating epoxy and exposed one side for electrochemical measurements. A solution $\left(0.05 \mathrm{M} \mathrm{H}_{2} \mathrm{SO}_{4}+2 \mathrm{ppm} \mathrm{HF}+0.01 \mathrm{M} \mathrm{NaCl}\right.$ solution) at $70{ }^{\circ} \mathrm{C}$ with $\mathrm{O}_{2}$ bubbling was used as an electrolyte to simulate the aggressive cathode environment of PEMFCs which were used in marine environment. The temperature of the corrosion tests was maintained by an isothermal bath during electrochemical tests. The electrochemical measurements were conducted in a CHI660C electrochemical workstation controlled by a computer. A typical three-electrode system was used for the electrochemical measurements: the specimens as the working electrode, a platinum sheet as the counter electrode and a saturated calomel electrode (SCE) connected to a Luggin capillary as the reference electrode. All specimens were stabilized at open-circuit potential for $30 \mathrm{~min}$ before electrochemical tests. The potentiodynamic test was carried out from $-0.6 \mathrm{~V}$ at a scanning rate of $1 \mathrm{mV} \mathrm{s}^{-1}$, and the potentiostatic test was performed at $0.6 \mathrm{~V}$ (vs. SCE) potential in the simulated cathode environment for $4 \mathrm{~h}$.
After $4 \mathrm{~h}$ potentiostatic polarization tests, the surface morphologies of untreated and W-modified 430 SS were obtained by confocal laser scanning microscope (CLSM) (Fv1200, Olympus Corporation, Japan). After $1 \mathrm{~h}$ immersion at open-circuit potential, the electrochemical impedance spectroscopy (EIS) test was carried out at opencircuit potential in a frequency range from $100 \mathrm{kHz}$ to $0.01 \mathrm{~Hz}$ with amplitude of $10 \mathrm{mV}$.

\section{Results and Discussion}

\subsection{Characteristics of the Tungsten Alloying Layer}

The surface morphology of the tungsten alloying layer is shown in Fig. 2a. It is evident that the surface of W-modified 430 SS produced by the plasma surface diffusion alloying technique is uniform, relatively smooth and dense without surface micropore and other common surface defects [24]. Figure $2 b$ shows a dense and continuous tungsten alloying layer with a thickness of about $8 \mu \mathrm{m}$ on the surface of W-modified $430 \mathrm{SS}$. In addition, the tungsten alloying layer also displays well metallurgical adhesion to the 430 SS substrate with a varying thickness of transition layer, which is beneficial to prolonging the service life of 430 SS as bipolar plates for PEMFCs compared with one produced by other surface modification techniques $[3,16,17]$. EDS linear scanning curves of tungsten, iron, and chromium elements varying from the surface of tungsten alloying layer to the substrate are shown in Fig. 2c. It is obvious that the tungsten alloying layer is about $8 \mu \mathrm{m}$, which confirms the result shown in Fig. $2 \mathrm{~b}$. During the plasma diffusion alloying process, tungsten atoms could be sputtered out from the source electrode and absorbed on the surface of the substrate due to the
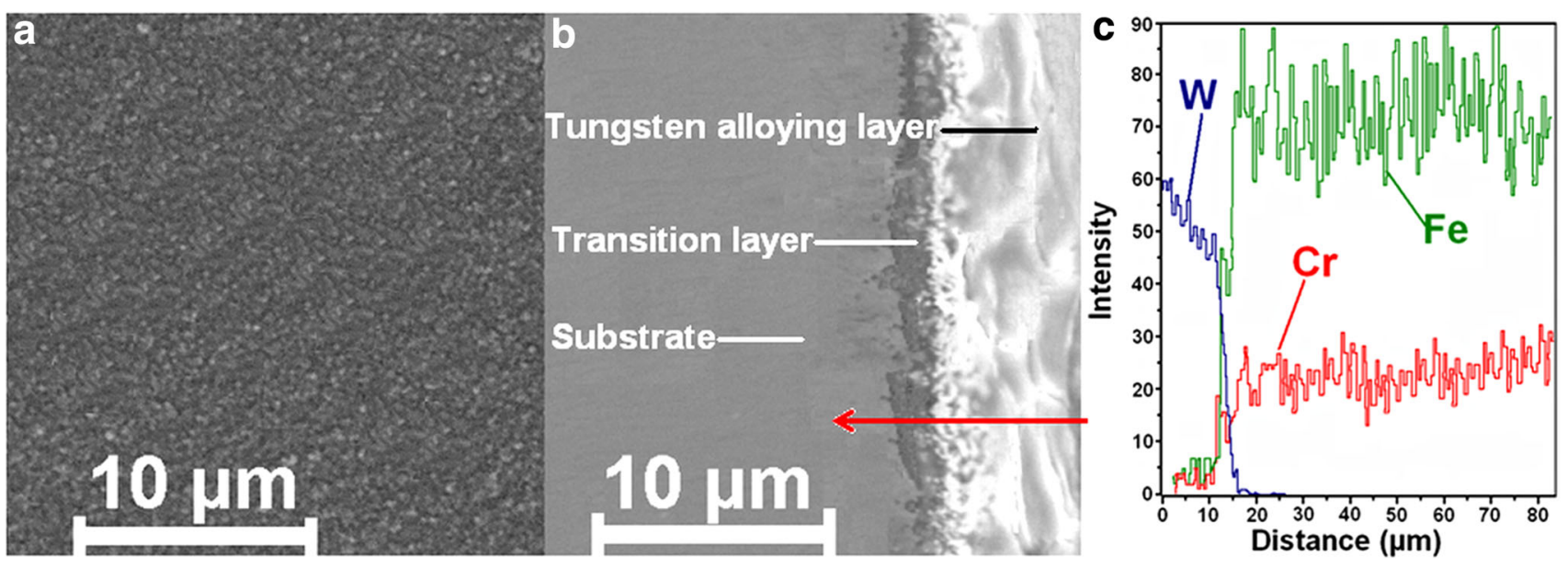

Fig. 2 a Surface morphology, b SEM image of the cross section and c EDS pattern for W-modified 430 SS 
bombardment of the argon ions and then diffuse into the substrate at high temperature. Meanwhile, a few iron and chromium atoms also could be sputtered out from the substrate at high temperature. Therefore, a transition layer could be formed between the substrate and the surface of W-modified 430 SS (Fig. 2b, c). Otherwise, as the provided tungsten atoms accumulated on the surface of the substrate, a $\mathrm{W}$ deposition layer with a thickness of 1-2 $\mu \mathrm{m}$ could be formed (Fig. 2c). Therefore, the formation process of tungsten alloying layer is affected by both the diffusion and deposition functions simultaneously.

Figure 3 shows XRD patterns of untreated and W-modified $430 \mathrm{SS}$. Obviously, there is no other impure phase of possible elements such as $\mathrm{Fe}$ or $\mathrm{Cr}$ in the XRD pattern of $\mathrm{W}$-modified $430 \mathrm{SS}$, indicating that tungsten atoms uniformly distributes on the surface of W-modified 430 SS. This result is in agreement with the above EDS linear scanning results (Fig. 2c). Considering that the corrosion occurs mainly on the surface of the specimen which

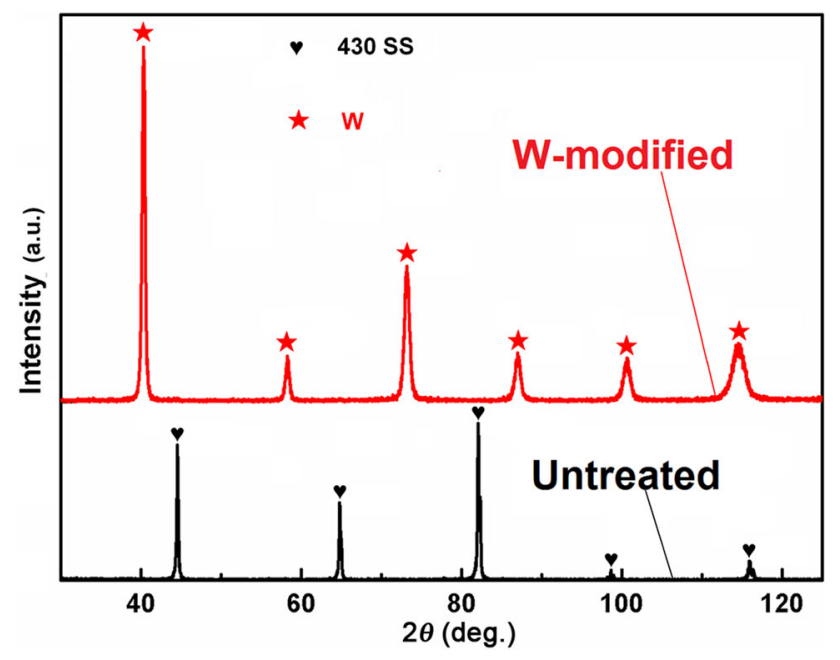

Fig. 3 XRD patterns of untreated and W-modified 430 SS is perfectly covered by a tungsten alloying layer after plasma surface diffusion alloying process, the corrosion resistance of the substrate has no effect on the corrosion of modified bipolar plates. Therefore, we choose AISI 430 SS which is low nickel as substrate to reduce the cost of PEMFC. Furthermore, the similar crystal structure of 430 SS and tungsten (body-centered cubic) is beneficial to form a better metallurgical adhesion.

\subsection{Hydrophilicity of the Specimen Surfaces}

In the PEMFC stacks, water would be generated owing to the hydrogen and oxygen electrochemical reaction [22]. In addition, to prevent the proton exchange membrane from dehydration, the inlet gases need to be humidified. Meanwhile, the exhaust gases are often mixed with the resultant water [8]. The liquid water could adhere to the bipolar plates, which not only blocks the reaction gases accessing to the electrode, but also accelerates the corrosion of the bipolar plates [8, 22]. From this view, the hydrophobicity of the bipolar plates is directly relevant to the properties of the PEMFCs. Bipolar plates with a superior hydrophobicity would be helpful for the process of removing the liquid water from the PEMFC stacks timely and beneficial to the simplification of water management [22]. Usually, a hydrophobic material displays a contact-angle more than $90^{\circ}$ between liquid-vapor and liquid-solid surfaces as a water droplet is placed onto its surface [25]. Figure $4 a, b$ shows the contact-angle with water of untreated and $\mathrm{W}$-modified $430 \mathrm{SS}$, respectively. The average contact-angle of untreated $430 \mathrm{SS}$ is $69.6^{\circ}$, while the $\mathrm{W}$-modified one is $93.5^{\circ}$. This result shows that the W-modified $430 \mathrm{SS}$ represents a better hydrophobicity, which provides enough contact-angle for electrochemical reaction, is also beneficial to the simplification of water management and reduces the corrosion of the bipolar plates [25].
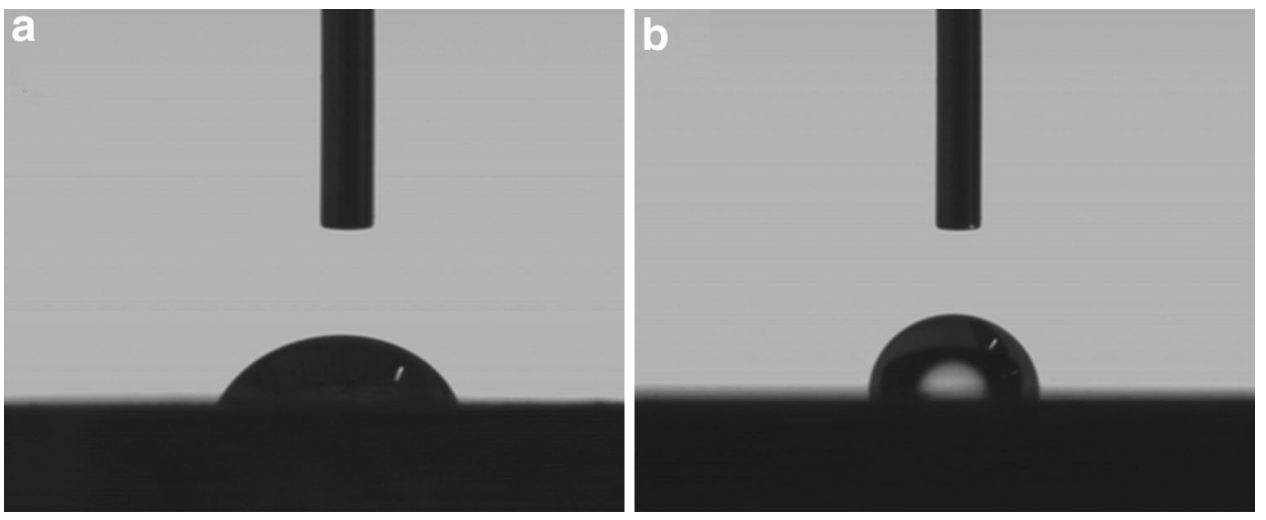

Fig. 4 Contact-angles with water of untreated a and W-modified 430 SS b 


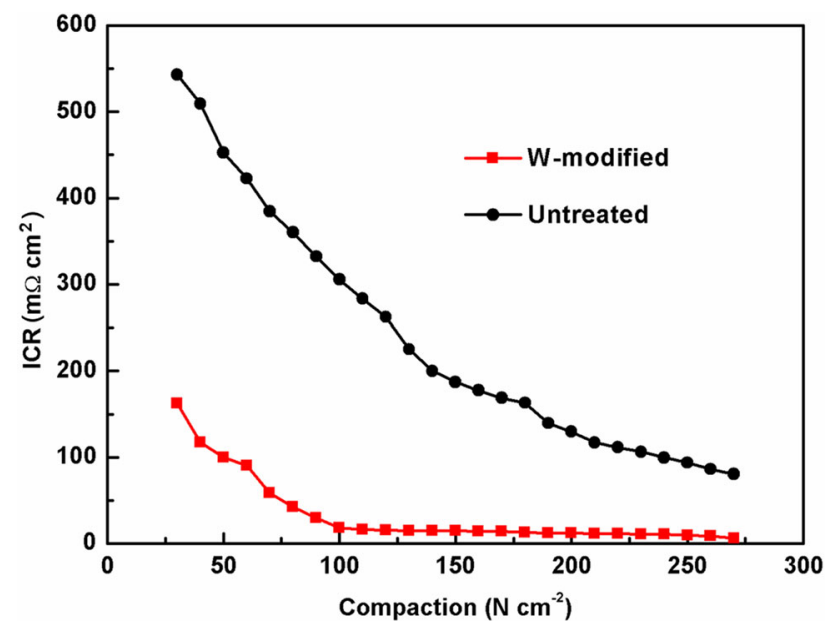

Fig. 5 ICR of untreated and W-modified 430 SS

\subsection{Interfacial Contact Resistance (ICR) of the Specimens}

The ICR, which primarily comes from the interface between bipolar plate and gas diffusion layer, is a key factor leading to the power output loss of PEMFC stack [18-20]. Figure 5 displays the ICR as a function of compaction force from 30 to $270 \mathrm{~N} \mathrm{~cm}^{-2}$ for untreated and $\mathrm{W}$-modified $430 \mathrm{SS}$. At lower compaction force, the ICR decreases markedly and then gradually stabilizes at the compaction forces more than $100 \mathrm{~N} \mathrm{~cm}^{-2}$. This is because the effective contact area does not increase further when the compaction forces are more than $100 \mathrm{~N} \mathrm{~cm}^{-2}$ and no apparent change is observed thereafter [3,27]. Compared with untreated $430 \mathrm{SS}$, the ICR of W-modified $430 \mathrm{SS}$ is significantly lower under all compaction forces.
Particularly, under the general applying compaction force of $140 \mathrm{~N} \mathrm{~cm}^{-2}$, the ICR of untreated $430 \mathrm{SS}$ is $199.96 \mathrm{~m} \Omega \mathrm{cm}^{2}$, which is an order of magnitude larger than that of W-modified $430 \mathrm{SS}\left(14.89 \mathrm{~m} \Omega \mathrm{cm}^{2}\right)$. All of these indicate that the $\mathrm{W}$-modified $430 \mathrm{SS}$ has higher surface conductivity and thus it could be a promising material for the bipolar plates of PEMFC [12].

\subsection{Potentiodynamic and Potentiostatic Polarization of the Specimens}

The corrosion resistance of the untreated and W-modified $430 \mathrm{SS}$ is characterized by potentiodynamic and potentiostatic polarization. The magnitude of corrosion current density which is equal to the rate of corrosion is the most direct way to estimate corrosion resistance in two polarization tests [26-28]. Figure 6a, b show the potentiodynamic and potentiostatic polarization curves of untreated and $\mathrm{W}$-modified $430 \mathrm{SS}$ in the simulated cathode environment of PEMFC, respectively. All of the studied specimens show passivation behavior, but the passive zone of $\mathrm{W}$-modified $430 \mathrm{SS}$ is much longer than that of untreated 430 SS, which demonstrates that the W-modified $430 \mathrm{SS}$ has a better corrosion resistance (Fig. 6a). Otherwise, a low peak of active-passive transition appears on the potentiodynamic polarization curve of $\mathrm{W}$-modified $430 \mathrm{SS}$, while a higher peak exhibits on the curve of the untreated one, implying that the $\mathrm{W}$-modified $430 \mathrm{SS}$ is easy to passivation [3]. Compared with untreated $430 \mathrm{SS}$, the W-modified one has a distinct decrease in corrosion current density in both Fig. 6a, b. The corrosion current density of W-modified $430 \mathrm{SS}$ under working voltage of cathode $\left(0.6 \mathrm{~V}_{\mathrm{SCE}}\right)$ is 2.07 and $2.50 \mu \mathrm{A} \mathrm{cm}^{-2}$ which approach the standard of DOE $\left(<1 \mu \mathrm{A} \mathrm{cm}^{-2}\right)$ in potentiodynamic and potentiostatic
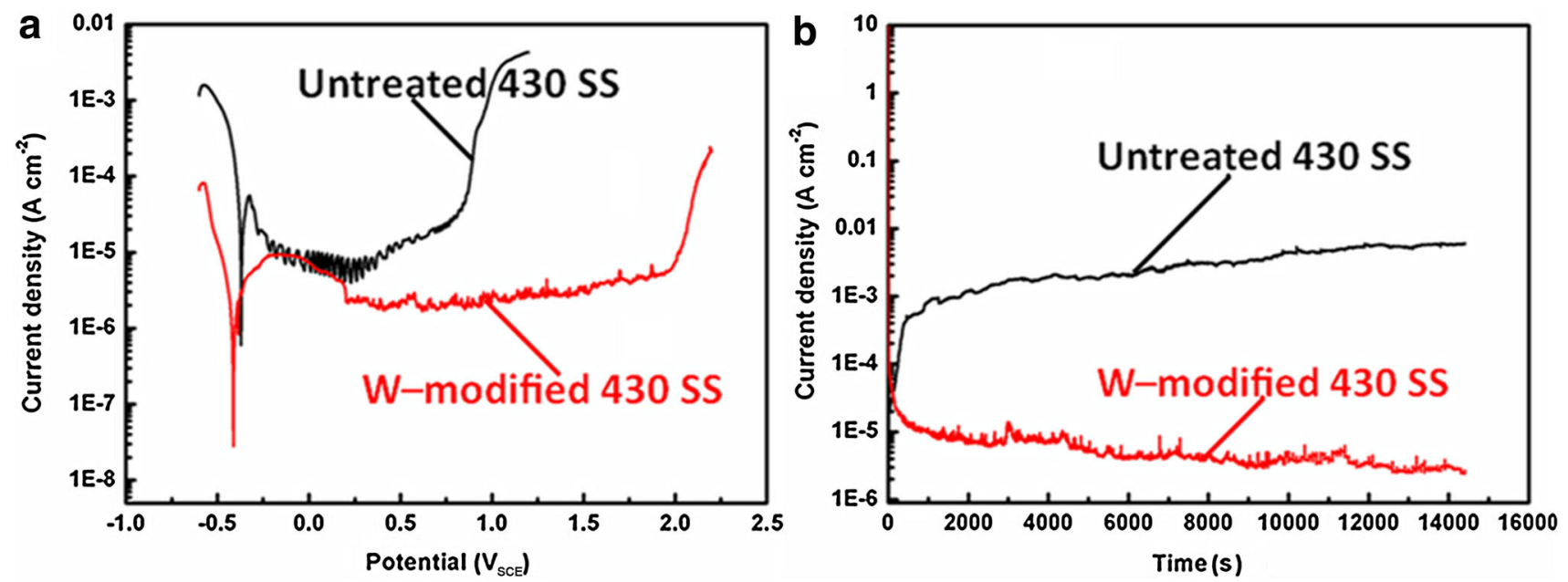

Fig. 6 a Potentiodynamic and b potentiostatic polarization curves of untreated and W-modified 430 SS in the simulated cathode environment of PEMFC 

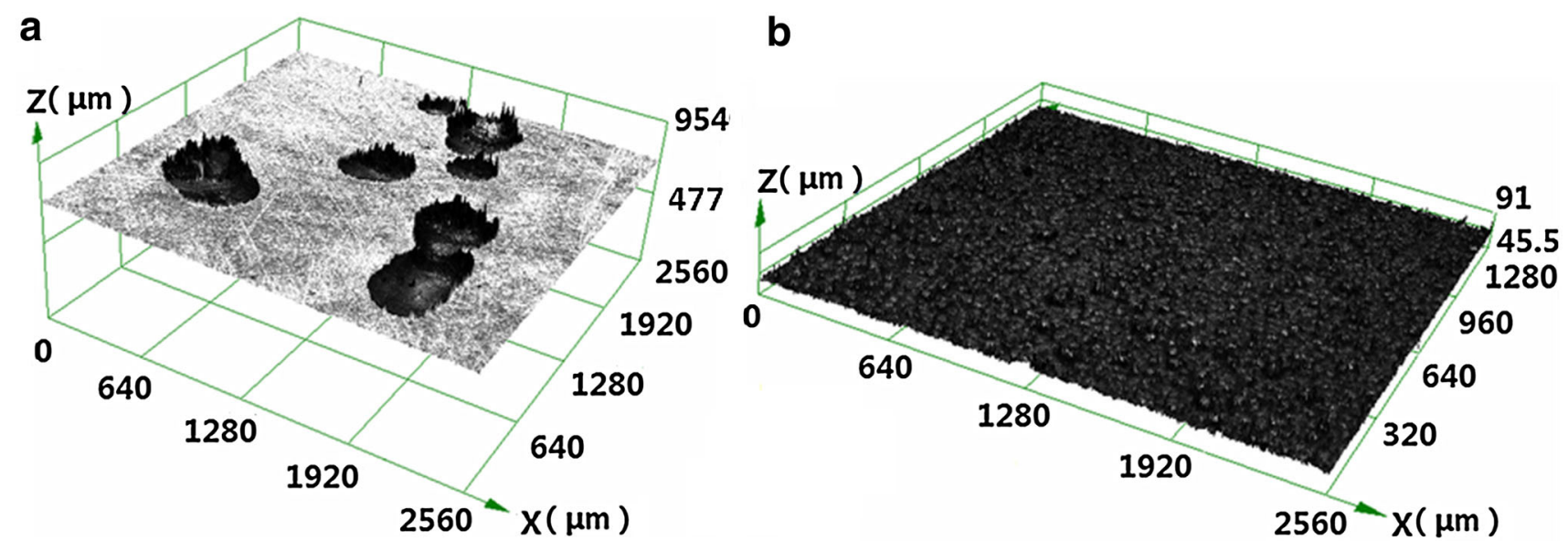

Fig. 7 Surface morphology of a untreated and b W-modified 430 SS after potentiostatic polarization tests in simulated cathode environment of PEMFC

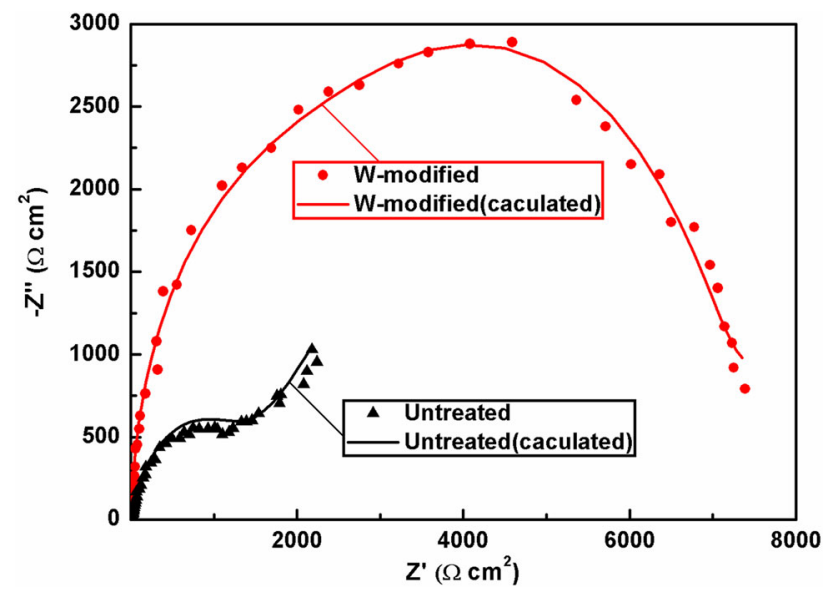

Fig. 8 Nyquist plots from untreated and W-modified 430 SS measured by EIS in the simulated cathode environment of PEMFC

polarization, respectively $[3,18]$, while the untreated 430 SS keeps on $15.8 \mu \mathrm{A} \mathrm{cm}^{-2}$ and $6.03 \mathrm{~mA} \mathrm{~cm}^{-2}$ in the same condition. Moreover, the gradually increasing corrosion current density on the potentiostatic polarization curve of untreated $430 \mathrm{SS}$ illustrates that there is an extremely weak passive protection for the untreated $430 \mathrm{SS}$ (Fig. 6b). The reason for these phenomena is that tungsten probably passes directly from the metal into passive film $\left(\mathrm{WO}_{3}\right)$ by interaction with pumped $\mathrm{O}_{2}$ and the formation of insoluble $\mathrm{WO}_{3}$ provides enhanced stability against aggressive ions $\left(\mathrm{SO}_{4}{ }^{2-}, \mathrm{F}^{-}\right.$and especially $\left.\mathrm{Cl}^{-}\right)$attack $[23,29]$. After potentiodynamic polarization test of $\mathrm{W}$-modified $430 \mathrm{SS}$, we could observe yellow precipitates in electrolyte and it may be sparingly soluble tungstic acid $\left(\mathrm{H}_{2} \mathrm{WO}_{4}\right)$. The $\mathrm{WO}_{4}{ }^{2-}$ as inhibitive ion in the electrolyte competes with aggressive ions $\left(\mathrm{SO}_{4}{ }^{2-}, \mathrm{F}^{-}\right.$and especially $\left.\mathrm{Cl}^{-}\right)$to adsorb a

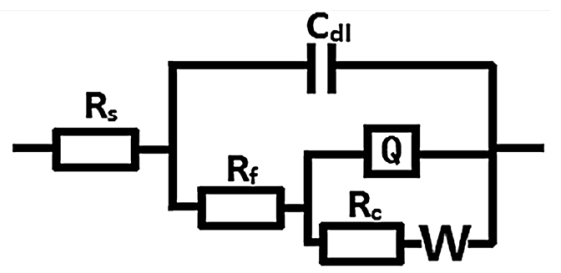

b

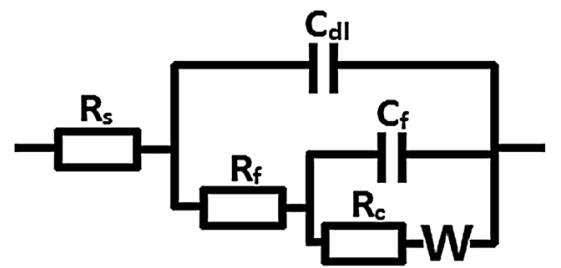

Fig. 9 Equivalent circuits of the corrosion system for $a$ untreated and $b$ W-modified $430 \mathrm{SS}$

on the surface of passive film. When the inhibitor ion is adsorbed on the surface of passive film, it plays a protective effect, while the adsorption of aggressive ions plays a corrosive effect [29]. However, the detailed mechanism is worthy of further discussion.

Figure $7 \mathrm{a}, \mathrm{b}$ show the surface morphology of untreated and $\mathrm{W}$-modified $430 \mathrm{SS}$ after the potentiostatic polarization tests, respectively. It is obvious to see that some large and deep holes can be observed on the surface of untreated 430 SS, accompanied by substantial evidence of material dissolution (Fig. 7a). However, the corroded surface of $\mathrm{W}$-modified 430 is relatively smooth with no evidence of pitting (Fig. 7b), suggesting that the passive film generated on the tungsten alloying layer is much tougher and offers better corrosion resistance in the simulated cathode environment of PEMFC. 
Table 1 Electrochemical parameters obtained from simulated equivalent circuits

\begin{tabular}{llllllll}
\hline Sample & $\begin{array}{l}R_{\mathrm{s}} \\
\left(\Omega \mathrm{cm}^{2}\right)\end{array}$ & $\begin{array}{l}R_{\mathrm{f}} \\
\left(\Omega \mathrm{cm}^{2}\right)\end{array}$ & $\begin{array}{l}C_{\mathrm{dl}} \\
\left(\Omega^{-1} \mathrm{~cm}^{-2} \mathrm{~S}^{-1}\right)\end{array}$ & $\begin{array}{l}R_{\mathrm{c}} \\
\left(\Omega \mathrm{cm}^{2}\right)\end{array}$ & $\begin{array}{l}Q \\
\left(\Omega^{-1} \mathrm{~cm}^{-2} \mathrm{~S}^{-n}\right)\end{array}$ & $\begin{array}{l}n \\
\left(\Omega^{-1} \mathrm{~cm}^{-2} \mathrm{~S}^{-1}\right)\end{array}$ & $\begin{array}{l}W \\
\left(\Omega^{-1} \mathrm{~S}^{-0.5} \mathrm{~cm}^{-2}\right)\end{array}$ \\
\hline Untreated & 16.19 & $1.00 \times 10^{-7}$ & $5.99 \times 10^{-8}$ & 1330 & $1.70 \times 10^{-4}$ & 0.8398 & - \\
W-modified & 15.54 & 4350 & $3.93 \times 10^{-5}$ & 2659 & - & - & $1.74 \times 10^{-4}$ \\
\hline
\end{tabular}

\subsection{Electrochemical Impedance Spectroscopy}

EIS is an effective method for studying the corrosion process of the electrical conductors in electrolytes under the low amplitude of its perturbation signal, which allows the monitoring of the electrode electrochemical behavior with time without altering its surface properties $[21,28,30]$. Figure 8 shows the Nyquist plots of untreated and W-modified $430 \mathrm{SS}$, and the lines are calculated results which fit quite good. Within the frequency range of the measurement, the Nyquist plots for W-modified $430 \mathrm{SS}$ display one parabola, while those for the untreated 430 SS present a high-frequency quarter circle and a low-frequency Warburg diffusion tail. In addition, the impedance spectra are analyzed using two different equivalent circuit models, as shown in Fig. 9(a) (for untreated $430 \mathrm{SS}$ ) and (b) (for $\mathrm{W}$-modified $430 \mathrm{SS}$ ), where $R_{\mathrm{S}}$ denotes the solution resistance between the reference and working electrode; $R_{\mathrm{c}}$ and $C_{\mathrm{dl}}$ denote the charge transfer resistance and doublelayer capacitance, respectively; $R_{\mathrm{f}}$ and $C_{\mathrm{f}}$ denote the resistance and capacitance of the passive film, respectively, and $W$ denotes the Warburg impedance [31]. Due to the non-ideal capacitive response of the interface between the solution and sample, a constant phase element (CPE), expressed as $Z_{\mathrm{CPE}}=(1 / Q)(j \omega)^{-n}$, is introduced to replace both $C_{\mathrm{dl}}$ and $C_{\mathrm{f}}$ in the fitting procedure, where $Q$ denotes the admittance magnitude of CPE, $j^{2}$ equals $-1, \omega$ is the angular frequency and $n$ is the exponential term. When $n=0, Z_{\mathrm{CPE}}$ presents the pure resistor impedance. Contrarily, when $n=1, Z_{\mathrm{CPE}}$ is equal to the pure capacitance impedance. Actually, $n$ is in the range from 0 to 1 , and $Q$ can be approximated by the capacitance [32]. Table 1 summarizes the electrochemical parameters obtained from simulated equivalent circuits. The solution resistances $\left(R_{\mathrm{S}}\right)$ of the two specimens are nearly equal in value, demonstrating similar ion conductivity in the test solutions. The resistance of the passive film $\left(R_{\mathrm{f}}\right)$ formed on the tungsten alloying layer is $4350 \Omega \mathrm{cm}^{2}$, which was an improvement of eleven orders of magnitude compared with untreated $430 \mathrm{SS}$. Otherwise, the W-modified $430 \mathrm{SS}$ has a larger $R_{\mathrm{c}}$ $\left(2659 \Omega \mathrm{cm}^{2}\right)$ which is the double of untreated one (1330 $\Omega \mathrm{cm}^{2}$ ), suggesting its superior corrosion resistance $[33,34]$. These improvements may be because the $\mathrm{WO}_{3}$ film and inhibitor ion $\left(\mathrm{WO}_{4}{ }^{2-}\right)$ generated during working process play a protective effect toward W-modified $430 \mathrm{SS}$ in the environment of PEMFC [23, 29].

\section{Conclusions}

In this study, a tungsten alloying layer with a thickness of 7-8 $\mu \mathrm{m}$ was fabricated on the surface of 430 SS via the plasma surface diffusion alloying method. Microstructure of the layer is dense, uniform and well bonding metallurgically with the substrate. Compared with untreated 430 $\mathrm{SS}$, the W-modified surface shows a higher contact angle of $93.5^{\circ}$ and a lower interfacial contact resistance, which are all beneficial to power efficiency. In the potentiodynamic and potentiostatic polarization tests, the corrosion current density of 430 SS all decreases after the plasma surface diffusion alloying process, which indicates that this technique could be used to improve the corrosion resistance of 430 SS in the simulated cathode environment of PEMFC. Furthermore, the W-modified 430 SS exhibits a charge transfer resistance of $2659 \Omega \mathrm{cm}^{2}$, which is the double of untreated one $\left(1330 \Omega \mathrm{cm}^{2}\right)$. After $4 \mathrm{~h}$ potentiostatic test, the serious corrosion occurs obviously on the surface of untreated $430 \mathrm{SS}$, while the corrosion degree of the $\mathrm{W}$-modified $430 \mathrm{SS}$ is very slight. The overall performance suggests that the W-modified 430 SS developed in this work has great potential to be used as the candidate bipolar plates for PEMFCs used in the marine environment.

Acknowledgments This work was financially supported by the National Natural Science Foundation of China (Nos. 51479019 and 21476035) and Fundamental Research Funds for Central Universities (No. 3132014323).

\section{References}

[1] H.C. Wang, H.H. Sheu, C.E. Lu, K.H. Hou, M.D. Ger, J. Power Sources 293, 475 (2015)

[2] M.C. Li, C.L. Zeng, H.C. Lin, C.A. Cao, Acta Metall. Sin. 38, 1287 (2002). (in Chinese)

[3] R.J. Tian, J.C. Sun, L. Wang, Int. J. Hydrog. Energy 31, 1874 (2006)

[4] H. Tsuchiya, O. Kobayashi, Int. J. Hydrog. Energy 29, 985 (2004)

[5] R.P. Vera Cruz, A. Nishikata, T. Tsuru, Corros. Sci. 40, 125 (1998) 
[6] M. Sun, M. Luo, C. Lu, T.W. Liu, Y.P. Wu, L.Z. Jiang, J. Li, Acta Metall. Sin. (Engl. Lett.) 28, 1089 (2015)

[7] Y. Tsutsumi, A. Nishikata, T. Tsuru, Corros. Sci. 49, 1394 (2007)

[8] J. Xu, H.J. Huang, Z.Y. Li, S. Xu, H.L. Tao, P. Munroe, Z.H. Xie, J. Alloys Compd. 663, 718 (2016)

[9] E.A. Cho, U.-S. Jeon, H.Y. Ha, S.-A. Hong, I.-H. Oh, J. Power Sources 125, 178 (2004)

[10] X.Q. Yan, M. Hou, H.F. Zhang, F.N. Jing, P.W. Ming, B.L. Yi, J. Power Sources 160, 252 (2006)

[11] S.R. Dhakate, S. Sharma, M. Borah, R.B. Mathur, T.L. Dhami, Int. J. Hydrog. Energy 33, 7146 (2008)

[12] H.L. Wang, M.A. Sweikart, J.A. Turner, J. Power Sources 115, 243 (2003)

[13] S.-J. Lee, C.-H. Huang, Y.-P. Chen, C.-T. Hsu, J. Fuel Cell Sci. Technol. 2, 290 (2005)

[14] M.P. Brady, K. Weisbrod, C. Zawodzinski, I. Paulauskas, R.A. Buchanan, L.R. Walker, Electrochem. Solid-State Lett. 5, A245 (2002)

[15] Y. Wang, D.O. Northwood, J. Power Sources 163, 500 (2006)

[16] W.-S. Jeon, J.-G. Kim, Y.-J. Kim, J.-G. Han, Thin Solid Films 516, 3669 (2008)

[17] A. Pozio, F. Zaza, A. Masci, R.F. Silva, J. Power Sources 179, 631 (2008)

[18] L.X. Wang, J.C. Sun, P.B. Li, B. Jing, S. Li, Z.S. Wen, S.J. Ji, J. Power Sources 208, 397 (2012)

[19] L.X. Wang, J.C. Sun, J. Renew. Sustain. Energy 5, 021407 (2013)

[20] L.X. Wang, J.C. Sun, J. Sun, Y. Lv, S. Li, S.J. Ji, Z.S. Wen, J. Power Sources 199, 195 (2012)
[21] L.X. Wang, J.C. Sun, B. Kang, S. Li, S.J. Ji, Z.S. Wen, X.C. Wang, J. Power Sources 246, 775 (2014)

[22] L.X. Wang, J.C. Sun, P.B. Li, J. Sun, Y. Lv, B. Jing, S. Li, S.J. Ji, Z.S. Wen, Int. J. Hydrog. Energy 37, 5676 (2012)

[23] L.X. Wang, J.C. Sun, S. Li, S.J. Ji, Z.S. Wen, B. Jing, Fuel Cells 6, 1131 (2013)

[24] K.S. Weil, G. Xia, Z.G. Yang, J.Y. Kim, Int. J. Hydrog. Energy 32, 3724 (2007)

[25] C.-Y. Chung, S.-K. Chen, T.-S. Chin, T.H. Ko, S.W. Lin, W.M. Chang, S.N. Hsiao, J. Power Sources 186, 393 (2009)

[26] M. Yadav, D. Behera, R.R. Sinha, P.N. Yadav, Acta Metall. Sin. (Engl. Lett.) 27, 37 (2014)

[27] A. Chabok, K. Dehghani, M.A. Jazani, Acta Metall. Sin. (Engl. Lett.) 28, 295 (2015)

[28] S. Jyothi, J. Ravichandran, Acta Metall. Sin. (Engl. Lett.) 27, 969 (2014)

[29] R.M. Saleh, M.M. Badran, A.A. Elhosary, H.A. Eldahan, Br. Corros. J. 23, 105 (1988)

[30] I. Frateur, C. Deslouis, M.E. Orazem, B. Tribollet, Electrochim. Acta 44, 4345 (1999)

[31] Z. He, F. Mansfeld, Energy Environ. Sci. 2, 215 (2009)

[32] X.J. Wu, H.Y. Ma, S.H. Chen, Z.Y. Xu, A.F. Sui, J. Electrochem. Soc. 146, 1847 (1999)

[33] W. Trabelsi, E. Triki, L. Dhouibi, M.G.S. Ferreira, M.L. Zheludkevich, M.F. Montemor, Surf. Coat. Technol. 200, 4240 (2006)

[34] K. Jüttner, W.J. Lorenz, M.W. Kendig, F. Mansfeld, J. Electrochem. Soc. 135, 332 (1988) 